\title{
Annotated Tissue
}

National Cancer Institute

\section{Source}

National Cancer Institute. Annotated Tissue. NCI Thesaurus. Code C48820.

A concise, detailed, description record of cell specimen(s) or tissues for clinical and laboratory applications. The information recorded contains explanatory guidelines or notes regarding the sample. This data collection enables multiple disciplines with special expertise in the diagnosis and treatment of carcinomas to facilitate the conduct of clinical- and laboratory-based cancer research. 